\title{
Safety of Acupuncture: Results of a Prospective Observational Study with 229,230 Patients and Introduction of a Medical Information and Consent Form
}

\author{
Claudia M. Witt ${ }^{\mathrm{a}}$ Daniel Pach ${ }^{\mathrm{a}}$ Benno Brinkhaus ${ }^{\mathrm{a}}$ Katja Wruck ${ }^{\mathrm{a}}$ Brigitte Tag ${ }^{\mathrm{b}}$ \\ Sigrid Mank $^{\mathrm{a}}$ Stefan N. Willich ${ }^{\mathrm{a}}$ \\ a Institute for Social Medicine, Epidemiology, and Health Economics, Charité University Medical Center, Berlin, Germany \\ ${ }^{\mathrm{b}}$ Chair of Criminal Law, Criminal Proceeding and Medical Law, University of Zurich, Switzerland
}

\section{Key Words}

Acupuncture · Safety · Adverse effects · Adverse events · Informed consent $\cdot$ Information and consent forms

\section{Summary}

Background: To evaluate the safety of acupuncture in a large number of patients receiving conventional health care and, based on these results, to develop a new medical consent form for acupuncture. Methods: The prospective observational study included patients who received acupuncture treatment for chronic osteoarthritis pain of the knee or hip, low back pain, neck pain or headache, allergic rhinitis, asthma, or dysmenorrhoea. After treatment, all patients documented adverse events associated with acupuncture (defined as adverse effects). Patients who reported a need for treatment due to an adverse effect completed an additional standardised questionnaire on the most important adverse effect. Based on this data and considering ethical and legal aspects a new consent form was developed. Results: A total of 229,230 patients received on average $10.2 \pm 3.0$ acupuncture treatments. Altogether, 19,726 patients $(8.6 \%)$ reported experiencing at least one adverse effect and 4,963 $(2.2 \%)$ reported one which required treatment. Common adverse effects were bleedings or haematoma $(6.1 \%$ of patients, $58 \%$ of all adverse effects), pain $(1.7 \%)$ and vegetative symptoms $(0.7 \%)$. Two patients experienced a pneumothorax (one needed hospital treatment, the other observation only). The longest duration of a side effect was 180 days (nerve lesion of the lower limb). The resulting medical consent form consists of five modules: Introduction to acupuncture and moxibustion, Risks of acupuncture treatment, Conditions which can increase the risk, Doctor's statement, and Consent. Conclusion: Acupuncture provided by physicians is a relatively safe treatment and the proposed consent form could support both patients and professionals in the process of obtaining informed consent.

\section{Schlüsselwörter}

Akupunktur · Sicherheit · Nebenwirkungen · Unerwünschte Ereignisse $\cdot$ Informierte Einwilligung · Aufklärungsbogen

\section{Zusammenfassung}

Hintergrund: Ziel der Studie war es, die Sicherheit von Akupunktur in einem großen Patientenkollektiv in der Normalversorgung zu untersuchen und auf Basis der resultierenden Daten einen Akupunkturaufklärungsbogen für die Normalversorgung zu entwickeln. Methoden: In eine prospektive Beobachtungsstudie wurden Patienten aufgenommen, die Akupunktur wegen folgender Diagnosen erhielten: chronische Schmerzen aufgrund von Osteoarthrose des Knies oder der Hüfte, Schmerzen der Lendenwirbelsäule, Kopfschmerzen und Schmerzen der Halswirbelsäule, allergische Rhinitis, Asthma und Dysmenorrhoe. Am Ende der Akupunkturbehandlung wurden alle Patienten nach Nebenwirkungen befragt, die sie mit der Akupunktur in Zusammenhang brachten. Patienten, die die Behandlungsbedürftigkeit einer Nebenwirkung berichteten, erhielten einen zusätzlichen Fragebogen zur bedeutendsten Nebenwirkung. Auf Grundlage dieser Daten und unter Beachtung von ethischen und juristischen Aspekten wurde ein Patientenaufklärungsbogen entwickelt. Ergebnisse: Insgesamt wurden 229230 Patienten in die Studie eingeschlossen. Die Patienten erhielten im Durchschnitt 10,2 $\pm 3,0$ Behandlungen. 19726 Patienten $(8,6 \%)$ berichteten von mindestens einer Nebenwirkung und $4963(2,2 \%)$ benötigten deswegen eine Behandlung. 24377 Nebenwirkungen wurden berichtet. Häufige Nebenwirkungen sind Blutungen oder Hämatome $6,1 \%$ der Patienten, $58 \%$ aller Nebenwirkungen) sowie Schmerz $(1,7 \%)$, gefolgt von vegetativen Symptomen $(0,7 \%)$. Bei 2 Patienten wurde ein Pneumothorax durch die Akupunktur verursacht. Ein Patient benötigte deswegen eine Krankenhausbehandlung, bei dem anderen genügte die weitere Beobachtung. Die mit 180 Tagen am längsten andauernde Nebenwirkung war eine Nervenläsion am Unterschenkel. Der resultierende Aufklärungsbogen umfasst fünf Module: Einführung in die Akupunktur und Moxibustion, Risiken der Akupunkturbehandlung, Bedingungen, die das Risiko erhöhen können, Ärztliche Anmerkungen und Einwilligung. Schlussfolgerung: Die von Ärzten durchgeführte Akupunktur ist eine relativ sichere Behandlungsform. Der vorgeschlagene Aufklärungsbogen könnte Patienten und Ärzte bei der Aufklärung vor der Einwilligung unterstützen.

\section{KARGER}

Fax +497614520714

Information@Karger.de

www.karger.com (c) 2009 S. Karger GmbH, Freiburg

Accessible online at:

www.karger.com/fok 


\section{Introduction}

Today, acupuncture is often used [1-3] and increasingly integrated into conventional care. It is administered on the basis of positive evidence for pain-related conditions such as osteoarthritis of the knee [4-6] as well as postoperative and chemotherapy-induced nausea and vomiting [7, 8]. Despite the lack of positive scientific evidence, it is also used for other conditions such as asthma [9] and smoking cessation [10]. But side effects, even severe ones like pneumothorax, cardiac tamponade, and infections can occur [11-22] and a patient should be informed about these. Some authors, however, point out that many of these events may have been caused by malpractice or negligence $[19,23,24]$ suggesting that they could be avoided.

An important part of health care (including acupuncture) consists of providing patient information and gaining informed consent. However, this is time consuming and therefore often neglected. Additionally, sometimes the scientific basis for this information is incomplete.

Informed consent is the legal basis for medical treatments. In Germany, any medical intervention is considered to contain the elements of the legal offence known as physical injury, as defined by $\S \S 223$ et seqq. StGB (Strafgesetzbuch, Criminal Code); 823 BGB (Bürgerliches Gesetzbuch, German Civil Code). This position, espoused by the Imperial Court of Justice (Reichsgericht) in 1894 (RGSt 25, 375), has been consistently maintained by the German Federal Court of Justice (Bundesgerichtshof) (BGHSt 35, 246) [25]. Yet, in order to gain adequate informed consent before acupuncture treatments, detailed patient information and a discussion about possible treatment risks associated with acupuncture is important. However, for this purpose valid data on the side effects of acupuncture and their frequency of occurrence is necessary.

Until recently, most data available was based on anecdotal reports [16] or on practitioners' self reports [18, 26-29]. The aim of the Acupuncture Safety and Health Economics Study (ASH) was to investigate safety in German usual care including self-reports of a large number of patients. The ASH was part of a large research initiative supported by the health sickness funds. The additional aim of this article is to provide a consent form for acupuncture which uses these new data to inform patients about possible side effects.

\section{Methods}

\section{Observational Study}

The prospective observational study included all out-patients (age $\geq 18$ years) from participating health sickness funds who received acupuncture treatment for chronic osteoarthritis pain of the knee or hip, low back pain, neck pain or headache, allergic rhinitis, asthma, or dysmenorrhoea between December 2000 and August 2004 [30, 31]. Acupuncture was provided by physicians with postgraduate acupuncture training of at least $140 \mathrm{~h}$. At the end of each treatment cycle, all patients were asked to complete a standardised questionnaire and to document adverse events they associated with acupuncture (defined as adverse effects) in free text and, if necessary, the kind of treatment they had needed (self-treatment, medication/physician treatment, treatment in hospital). Adverse events without association to the acupuncture treatment were not documented. Patients who reported adverse effects which needed treatment, received from the study office an additional, more detailed standardised questionnaire concerning their most important adverse effect.

For analysis, adverse effects were categorised by specially trained staff using categories which were developed in a consensus process between MDs, acupuncturists, epidemiologists and psychologists.

\section{Development of the Consent Form}

The frequency of adverse effects was classified according to the guidelines of the European Commission used to describe adverse effects of medicinal products (very common $(\geq 1 / 10)$; common $(\geq 1 / 100$ to $<1 / 10)$; uncommon $(\geq 1 / 1,000$ to $\leq 1 / 100)$; rare $(\geq 1 / 10,000$ to $\leq 1 / 1,000)$; very rare $(\leq 1 / 10,000)$, not known) [32].

On the basis of the study results, existing material (www.uni-essen/ naturheilkunde), and considering ethical and legal aspects of informed consent [20, 25, 33, 34], a consent form on medical acupuncture was developed. Besides information about the patient's ailment, the nature of the proposed treatment, the benefits of the treatment, and reasonable treatment alternatives we focused on detailed information about risks similar to the European medicinal product information [32] used in European patient information leaflets.

The ASH study was approved by the appropriate ethics committees and all patients provided written informed consent. SPSS 11.5 (SPSS Inc., Chicago, IL, USA) was used for data analysis.

\section{Results}

\section{Observational Study}

A total of 13,579 physicians (mean age $46.0 \pm 7.4,61.1 \%$ male) practising acupuncture in Germany participated in the present study. All physicians had at least $140 \mathrm{~h}$ of acupuncture training (German A diploma) and on average $6.9 \pm 5.3$ years of acupuncture practice, $15.4 \%$ had $\geq 350 \mathrm{~h}$ of training (German B diploma). Half of the physicians (48.3\%) were general practitioners, $18.8 \%$ orthopaedists, $10.4 \%$ internists, $4.5 \%$ anaesthetists, $4.4 \%$ gynaecologists, and $13.6 \%$ had other specialisations. On average, they treated $11.7 \pm 15.7 \%$ of their patients with acupuncture.

229,230 patients (mean age $51.0 \pm 14.3$ years (95\% CI 51.0 $51.1), 64.8 \%$ female) were enrolled and received on average $10.17 \pm 3.0$ (10.16-10.18) acupuncture treatments. The analysis is thus based on 2.2 million acupuncture sessions. Altogether, 19,726 patients (8.6\%) reported experiencing at least 1 adverse effect. Adverse effects requiring treatment occurred in $2.2 \%$ of patients $(n=4,963)$. Overall, 24,377 adverse effects were reported. Common adverse effects were minor bleeding or haematoma $(6.1 \%)$ and pain $(1.7 \%)$ followed by vegetative symptoms $(0.7 \%)$ (table 1$)$. Bleeding or haematoma was the predominant adverse effect $(58 \%$ of all adverse effects, fig. 1). Adverse effects which indicate negligence or malpractice (broken or forgotten needle, pneumothorax, burns after moxibustion) occurred in $0.1 \%$ of all adverse effects.

Of the adverse effects $39.4 \%$ occurred during and $60.6 \%$ after the treatment sessions. Two cases of pneumothorax occurred, both immediately after and caused by acupuncture; 
Fig. 1. ASH study: Most frequent adverse effects of acupuncture in condensed categories.

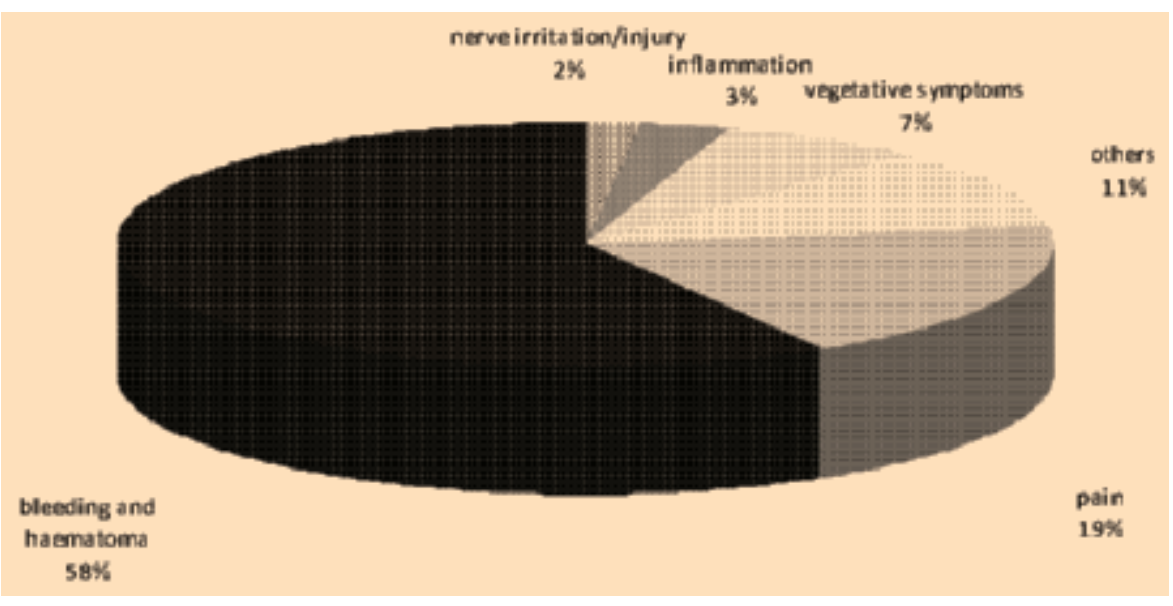

Table 1. Acupuncture adverse effects; total study population: $n=229,230$

\begin{tabular}{|c|c|c|c|c|c|c|c|}
\hline & \multicolumn{2}{|c|}{ Frequency } & \multicolumn{2}{|c|}{ No need for treatment } & \multicolumn{2}{|c|}{ Need for treatment } & \multirow[t]{2}{*}{ Frequency in text form ${ }^{\mathrm{a}}$} \\
\hline & $\mathrm{N}$ & $\%$ & $\mathrm{n}$ & $\%$ & $\mathrm{n}$ & $\%$ & \\
\hline Bleeding/haematoma & 14083 & 6.144 & 11468 & 5.00 & 2615 & 1.14 & common \\
\hline Inflammation & 711 & 0.310 & 382 & 0.17 & 329 & 0.14 & uncommon \\
\hline Inflammation at application site & 680 & 0.297 & 375 & 0.16 & 305 & 0.13 & uncommon \\
\hline Local infection & 31 & 0.014 & 7 & 0.003 & 24 & 0.01 & rare \\
\hline Pain & 4681 & 2.042 & 2209 & 0.96 & 2472 & 1.08 & common \\
\hline Headache & 1200 & 0.523 & 462 & 0.20 & 738 & 0.32 & uncommon \\
\hline Aggravation of symptoms, symptomatology & 712 & 0.311 & 384 & 0.17 & 328 & 0.14 & uncommon \\
\hline Local muscle pain & 548 & 0.239 & 261 & 0.11 & 287 & 0.13 & uncommon \\
\hline Strong pain during needling & 490 & 0.214 & 283 & 0.12 & 207 & 0.09 & uncommon \\
\hline Generalised muscle pain & 73 & 0.032 & 23 & 0.01 & 50 & 0.02 & rare \\
\hline Other pain & 1658 & 0.723 & 796 & 0.35 & 862 & 0.38 & uncommon \\
\hline Vegetative symptoms & 1663 & 0.725 & 873 & 0.38 & 790 & 0.34 & uncommon \\
\hline Vertigo & 514 & 0.224 & 256 & 0.11 & 258 & 0.11 & uncommon \\
\hline Nausea & 332 & 0.145 & 177 & 0.08 & 155 & 0.07 & uncommon \\
\hline Sweating & 96 & 0.042 & 56 & 0.02 & 40 & 0.02 & rare \\
\hline Depression of blood pressure & 86 & 0.038 & 42 & 0.02 & 44 & 0.02 & rare \\
\hline Unconsciousness & 62 & 0.027 & 35 & 0.02 & 27 & 0.01 & rare \\
\hline Tachycardia & 47 & 0.021 & 24 & 0.01 & 23 & 0.01 & rare \\
\hline Breathing difficulties & 35 & 0.015 & 22 & 0.01 & 13 & 0.01 & rare \\
\hline Increase in blood pressure & 30 & 0.013 & 11 & 0.005 & 19 & 0.01 & rare \\
\hline Constipation & 8 & 0.003 & 0 & 0.00 & 8 & 0.003 & very rare \\
\hline Palpitations & 6 & 0.003 & 6 & 0.003 & 0 & 0.00 & very rare \\
\hline Enterospasm & 4 & 0.002 & 4 & 0.002 & 0 & 0.00 & very rare \\
\hline Weight reduction & 2 & 0.001 & 2 & 0.0009 & 0 & 0.00 & very rare \\
\hline Circulatory disturbance & 1 & 0.0004 & 1 & 0.0004 & 0 & 0.00 & very rare \\
\hline Other cardiac or circulatory disturbance & 440 & 0.192 & 237 & 0.10 & 203 & 0.09 & uncommon \\
\hline Nerve irritation/injuries & 601 & 0.262 & 350 & 0.15 & 251 & 0.11 & uncommon \\
\hline Paraesthesia & 221 & 0.096 & 125 & 0.05 & 96 & 0.04 & rare \\
\hline Hypaesthesia & 181 & 0.079 & 124 & 0.05 & 57 & 0.02 & rare \\
\hline Nerve irritation & 130 & 0.057 & 74 & 0.03 & 56 & 0.02 & rare \\
\hline Paresis & 38 & 0.017 & 14 & 0.01 & 24 & 0.01 & rare \\
\hline Nerve injury & 31 & 0.014 & 13 & 0.01 & 18 & 0.01 & rare \\
\hline Others & 2638 & 1.151 & 1302 & 0.57 & 1336 & 0.58 & common \\
\hline Fatigue & 491 & 0.214 & 315 & 0.14 & 176 & 0.08 & uncommon \\
\hline Swelling & 346 & 0.151 & 145 & 0.06 & 201 & 0.09 & uncommon \\
\hline Worsening health state & 209 & 0.091 & 112 & 0.05 & 97 & 0.04 & rare \\
\hline
\end{tabular}




\begin{tabular}{|c|c|c|c|c|c|c|c|}
\hline Other dermal phenomena & 205 & 0.089 & 92 & 0.04 & 113 & 0.05 & rare \\
\hline Itching & 174 & 0.076 & 98 & 0.04 & 76 & 0.03 & rare \\
\hline Other neurological complaints & 159 & 0.069 & 66 & 0.03 & 93 & 0.04 & rare \\
\hline Redness & 147 & 0.064 & 102 & 0.04 & 45 & 0.02 & rare \\
\hline Restricted movement & 117 & 0.051 & 52 & 0.02 & 65 & 0.03 & rare \\
\hline Sleep disturbance & 97 & 0.042 & 40 & 0.02 & 57 & 0.02 & rare \\
\hline Joint problems & 71 & 0.031 & 35 & 0.02 & 36 & 0.02 & rare \\
\hline Other mood swings & 71 & 0.031 & 25 & 0.01 & 46 & 0.02 & rare \\
\hline Anxiety & 55 & 0.024 & 22 & 0.01 & 33 & 0.01 & rare \\
\hline Vomiting & 49 & 0.021 & 11 & 0.005 & 38 & 0.02 & rare \\
\hline Restlessness/nervousness & 45 & 0.020 & 28 & 0.01 & 17 & 0.01 & rare \\
\hline Disturbed vision & 45 & 0.020 & 19 & 0.01 & 26 & 0.01 & rare \\
\hline Other gastrointestinal complaints & 45 & 0.020 & 15 & 0.01 & 30 & 0.01 & rare \\
\hline Feeling of coldness & 36 & 0.016 & 14 & 0.01 & 22 & 0.01 & rare \\
\hline Depressive mood & 35 & 0.015 & 9 & 0.004 & 26 & 0.01 & rare \\
\hline Menstrual problems & 32 & 0.014 & 17 & 0.01 & 15 & 0.01 & rare \\
\hline Tinnitus & 23 & 0.010 & 7 & 0.003 & 16 & 0.01 & rare \\
\hline Gastrospasm & 19 & 0.008 & 8 & 0.003 & 11 & 0.005 & very rare \\
\hline Diarrhoea & 16 & 0.007 & 4 & 0.002 & 12 & 0.01 & very rare \\
\hline Imbalance & 15 & 0.007 & 6 & 0.003 & 9 & 0.004 & very rare \\
\hline Burns after moxibustion & 14 & 0.006 & 4 & 0.002 & 10 & 0.004 & very rare \\
\hline Shivering & 13 & 0.006 & 9 & 0.004 & 4 & 0.002 & very rare \\
\hline Needle forgotten & 12 & 0.005 & 8 & 0.003 & 4 & 0.002 & very rare \\
\hline Poor concentration & 9 & 0.004 & 3 & 0.001 & 6 & 0.003 & very rare \\
\hline Eye irritation & 6 & 0.003 & 2 & 0.001 & 4 & 0.002 & very rare \\
\hline Lesion of blood vessels & 5 & 0.002 & 3 & 0.001 & 2 & 0.001 & very rare \\
\hline Systemic infection & 5 & 0.002 & 2 & 0.001 & 3 & 0.001 & very rare \\
\hline Nightmares & 4 & 0.002 & 2 & 0.001 & 2 & 0.001 & very rare \\
\hline Euphoria & 3 & 0.001 & 1 & 0.0004 & 2 & 0.001 & very rare \\
\hline Disturbance of speech & 3 & 0.001 & 1 & 0.0004 & 2 & 0.001 & very rare \\
\hline Needle broken & 2 & 0.001 & 0 & 0.00 & 2 & 0.001 & very rare \\
\hline Pneumothorax & 2 & 0.001 & 0 & 0.00 & 2 & 0.001 & very rare \\
\hline Disorientation & 2 & 0.001 & 2 & 0.001 & 0 & 0.00 & very rare \\
\hline Other adverse events & 56 & 0.024 & 23 & 0.01 & 33 & 0.01 & rare \\
\hline
\end{tabular}

${ }^{a}$ According to the guidelines of the European Commission used to describe adverse effects of medicinal products (very common ( $\left.\geq 1 / 10\right)$; common $(\geq 1 / 100$ to $<1 / 10)$; uncommon $(\geq 1 / 1,000$ to $\leq 1 / 100)$; rare $(\geq 1 / 10,000$ to $\leq 1 / 1,000)$; very rare $(\leq 1 / 10,000)$, not known) [32].

one patient required hospital treatment, the other was less seriously affected and required observation, only. The longest duration of a side effect was 180 days (nerve lesion of the lower limb). There were no acupuncture-associated deaths or permanent injuries associated with the acupuncture treatments.

\section{Development of the Consent Form}

The medical acupuncture consent form that has been developed consists of five modules: Introduction into acupuncture and moxibustion, Risks of acupuncture treatment, Conditions which can increase the risk, Doctor's statement, and Consent.

We decided to provide modules in order to allow that parts can be included in existing consent forms. Risks are shown in English (fig. 2), since they are relatively independent of country-specific influences. There is a free download of the full German version at www.karger.com/doi/10.1159/000209315 and www.charite.de/cam). The authors regret that they cannot assume liability for errors or omissions. Ideally, patients should be informed $24 \mathrm{~h}$ prior to the first acupuncture session.

\section{Discussion}

The data from the observational study presented here show a variety of adverse effects accompanying acupuncture provided by German physicians. These adverse effects were not rare and occurred in $8.6 \%$ of the sampled patients. However, most of them were only minor events, like bleedings or haematoma, pain or vegetative symptoms. However, very severe side effects such as pneumothorax or nerve lesions do occur and patients should be made aware of them. The medical consent form for acupuncture made up of five modules, including information on possible side effects, is the first to provide information for the patient similar to instruction leaflets enclosed in any European box of medication.

The analysis is based on a large sample of 229,230 patients with more than 2 million acupuncture sessions in usual care setting. Moreover, in this study all patients from participating health sickness funds who received acupuncture treatment reported adverse effects directly. This study setting allows to 


\section{Risks of acupuncture treatment}

Like all treatments, acupuncture can cause side effects. The following ranking is used:

Very common: more than 1 out of 10 treated people

Common: 1 to 10 out of 100 treated people

Uncommon: 1 to 10 out of 1,000 treated people

Rare: 1 to 10 out of 10,000 treated people

Very rare: less than 1 out of 10,000 treated people, including singular incidents

The character of possible side effects also depends on the acupuncture points which were chosen for treatment. Please ask your doctor which points he or she will use. The following symptoms were experienced by patients treated with acupuncture:

Common: 1 to 10 out of 100 people treated

Common side effects are bleeding and haematoma because of the lesion of small vessels. Sometimes, small bleedings are a desired part of Chinese acupuncture treatment.

Uncommon: 1 to 10 of 1,000 treated people

Uncommon side effects observed in the context of acupuncture treatment include: inflammation at the application site, swelling, strong pain during needling, and local muscle pain. Nerve irritation or nerve injury is also possible. This can cause sensation difficulties or a temporary weakness in the associated musculature. Furthermore, headache, fatigue, and vegetative symptoms like vertigo and nausea were experienced. An initial aggravation of the symptoms which lead to the treatment is possible.

Rare: 1 to 10 out of 10,000 people treated

Rare side effects include: local infection, redness, itching, sweating, decrease of blood pressure, increase in blood pressure, unconsciousness, tachycardia, breathing difficulties, vomiting, worsening health state, generalized muscle pain, restricted movement, joint problems, feeling of coldness, menstrual problems, depressive mood, anxiety, sleep disturbance, restlessness/ nervousness, disturbed vision and tinnitus.

Very rare: less than 1 out of 10,000 treated people, including singular incidents Side effects observed in the context of acupuncture treatment include: palpitations, constipation, diarrhoea, gastrospasm, enterospasm, weight loss, circulatory disturbance, lesion of blood vessels, systemic infection, euphoria, nightmares, poor concentration, imbalance, disturbance of speech, disorientation, shivering, and eye irritation. Very rarely acupuncture needles can be forgotten or break. During treatment on the thorax a too deep insertion of an acupuncture needle can cause accumulation of air in the pleural cavity (pneumothorax). In the scientific literature injuries of the central nervous system and the pericardium have been reported.

The application of heat through burning mugwort (moxibustion) can cause burns.

Some of the side effects mentioned above can influence your fitness to drive!

If side effects occur during or after treatment, please inform your doctor.

Fig. 2. Risks of acupuncture treatment

recognise very rare complications, reflects acupuncture performed by physicians in Germany, and helps minimise underreporting [35] and selection bias. Nonetheless, direct patient reports do have certain limitations - e.g. recall bias, overreporting, coincidence of acupuncture and undesirable effects, or vague causality - and there was no control group. Furthermore, only patients with chronic osteoarthritis pain of the knee or hip, low back pain, neck pain or headache, allergic rhinitis, asthma, or dysmenorrhoea were included in the study and auricular acupuncture or electro-stimulation were not performed. Nevertheless, these patients represent most of the patients treated with acupuncture in Germany.

The type and frequency of adverse effects are difficult to compare between the various studies which evaluate acupuncture adverse effects [12]. Studies can vary in many ways including, among others, in the observed acupuncture technique, the number and type of patients included, the number of reported sessions, the training of the acupuncturist (MD vs. non-MD) and the conditions treated with acupuncture. Moreover, the methods used to define and document adverse effects differ. Both, physician and/or patient information are used to report adverse effects, after every session, after a treatment cycle, or, irrespective of the individual patient, all adverse effects in a certain time frame. Therefore, the incidence of adverse effects can be described per patient or per treatment session. However, we think two studies are comparable $[28,35]$ to our study, because they used either direct reports from patients of a large sample or included a comparably large sample of patients.

In 2002, MacPherson et al. [35] conducted a survey on the adverse events of acupuncture and also used direct reports of a large sample of patients. Of 9,408 recruited acupuncture 
patients, 6,348 completed a questionnaire concerning adverse events after 3 months. The achieved sample reported an average of 4.8 acupuncture visits over the 3 months corresponding to a total of 30,196 consultations for the whole sample. $682 \mathrm{pa}-$ tients $(10.7 \%)$ reported a total of 1,044 adverse events caused directly by the acupuncture treatment, with severe tiredness or exhaustion and prolonged or unacceptable pain at the site of needling as the most frequent adverse events. Less than 10 visits, which was the average number of visits in our study, were reported. The percentage of patients reporting adverse effects was about $20 \%$ higher than the $8.6 \%(19,726)$ we found. In terms of the guidelines of the European Commission, used to describe adverse effects of medicinal products, MacPherson's data would rate acupuncture adverse effects as 'very common' whereas our results suggest them to be 'common'. The frequency of specific adverse effects like fatigue or headache was different compared to our data. One possible explanation for the differences is that MacPherson et al. used checklists with tick boxes, which may have produced a higher reporting compared to the free text form we used. An interesting question is whether the difference between our results and those of MacPherson can be explainded by the different type of provider. MacPherson et al. included non-physician acupuncturists whereas in our study, only physicians were included. Another study by MacPherson et al. [18], however, showed that the frequency of significant adverse events was comparable to that observed in a study by White et al. [36] which included doctors and physiotherapists (MacPherson: 1.3 per 1,000 treatments vs. White: 14 per 10,000 consultations).

The study by Melchart et al. [28] included 9,429 German physician acupuncturists of whom 7,050 reported adverse effects from 97,733 patients and approximately 760,000 sessions with an average of 7.8 acupuncture sessions per patient. They observed mild adverse effects in $7.1 \%$ of the patients, with needling pain and haematoma as the predominant effects. About $15 \%$ less adverse effects than in our study were observed, possibly because of underreporting by physicians. Needling pain $(3,202,3.28 \%)$, however, was much more often reported than in our study $(490,0.21 \%)$. One possible explanation for this difference is the use of a tick box for needling pain.

Most of the very severe complications mentioned in the literature, e.g. cardiac tamponade or spinal cord injury [19, $21,37]$, were not reported in our study. On the other hand, pneumothorax was observed both in our study and in that of Melchart [28]. It is a possible complication which can be caused by the care provider, but also by the patients who can accidentally push a punctured needle deeper into the thorax with a blanket or towel used to keep them warm. Nerve lesions are also known significant complications [14, 15, 21, 38] which were also observed in our study, however, these were not permanent injuries. Skin infections are adverse effects [15, 35] which might be avoidable. Tiredness or drowsiness, which was less observed in our study than it that by MacPherson et al. [35], is also a relevant adverse effect, because it affects the fitness to drive. In order to avoid unconsciousness or needle fainting, special care should be taken when inserting needles in a standing or sitting position or when a patient stands or sits up quickly after a treatment if the patient has little or no experience receiving acupuncture [19].

For the interpretation of events which we did not observe in our study but which are known from the literature, we can use a formula from Hanley and Lippman-Hand [39, 40]. According to this formula, a sample size needs to be 3 times $n$ to have a $95 \%$ probability that no severe complication occurs in n treatments $[18,39,40]$. This shows that even with the high number of patients in our study, it is difficult to draw conclusions for extremely rare events. But we can state that the highest risk of experiencing an adverse effect which we did not observe in our study is about 1 in 76,000 patients, with $95 \%$ probability. We think, very severe complications should not be overestimated but nonetheless, physicians and patients should be aware of them.

In out-patient care, the use of medical consent forms is especially difficult, because it is not an established practice; it is time consuming and seems impersonal. However, we want to motivate hospital and practice physicians to use an acupuncture consent form to standardise patient information.

Balancing the patients' needs for information and the legal aspects while avoiding information overload, was a difficult task in the process of developing the medical consent form. On the one hand the information should be clear and easy to understand for patients and doctors, but on the other hand, it should be detailed enough to fulfil all criteria in terms of content and legal aspects $[25,34]$. Consequently, the present consent form is a compromise. We decided to use the data from the ASH study as a basis. This data should represent the risk profile of most German patients treated with acupuncture in Germany and can help patients and physicians estimate the risk of adverse effects more accurately.

It is interesting to note that similar conventional interventions such as blood taking, injections or inserting peripheral intravenous lines are mostly performed without written informed consent, i.e. only verbal consent is obtained. One explanation might be that in most Western countries, acupuncture is not yet part of conventional university medical education or medical care, although it is becoming more and more common and increasingly integrated. Acupuncture is also used for the treatment of conditions although there is no clear scientific evidence of its efficacy in this context. A comprehensible process of gaining informed consent could improve patient information and help avoid legal disputes. The presented data and the proposed consent form may help achieve this aim.

However, the process of gaining informed consent does take time which could otherwise be used for a more intense patient-doctor interaction. And the question has to be answered what better helps to improve treatment safety: more bureaucracy or more time for intensive doctor-patient interactions? In order to allow flexible use of the information and 
consent form we propose a framework consisting of five modules which can be adapted according to condition and the individual patient. The modules or parts of them can also be included in existing consent forms. Routine reporting of severe adverse effects could help to keep the data up-to-date.

\section{Acknowledgements}

We would like to thank Iris Bartsch, Beatrice Eden and Susanne Jena for their assistance with data acquisition, the members of the advisory board (Dr. Konrad Beyer, Dr. Josef Hummelsberger, Hardy Müller, Dr. Albrecht Molsberger, Dr. Helmut Rüdinger, Dr. Wolfram Stör, Dr. Gabriel Stux) for their helpful advice, Miriam Ortiz for the critical review of the information and consent form and we thank all physicians and patients for their participation in the ASH study.

Role of the Sponsor: None of the supporting organizations or sponsors played any role in the design or conduct of the study; in the collection, management, analysis, or interpretation of the data; or in the preparation, review, or approval of the manuscript.

Funding: This study was funded by a number of German health sickness funds: the Techniker Krankenkasse (TK); Betriebskrankenkasse (BKK) Aktiv; Bosch BKK; DaimlerChrysler BKK; Bertelsmann BKK; BKK BMW; Siemens-Betriebskrankenkasse (SBK); BKK Deutsche Bank; BKK Hoechst; HypoVereinsbank BKK; Ford BKK; Betriebskrankenkasse der Allianz Gesellschaften; Vereins- und Westbank BKK; Handelskrankenkasse (HKK); Innungskrankenkasse (IKK) Hamburg Conflict of Interest: None

\section{References}

1 Eisenberg DM, Davis RB, Ettner SL, Appel S, Wilkey S, Van Rompay M, et al: Trends in alternative medicine use in the United States, 1990-1997: results of a follow-up national survey. JAMA 1998; 280:1569-1575.

2 Härtel U, Volger E: Inanspruchnahme und Akzeptanz klassischer Naturheilverfahren und alternativer Heilmethoden in Deutschland - Ergebnisse einer repräsentativen Bevölkerungsstudie. Forsch Komplementärmed Klass Naturheilkd 2004;11:327-334.

$\checkmark 3$ Kessler RC, Davis RB, Foster DF, Van Rompay MI, Walters EE, Wilkey SA, et al: Long-term trends in the use of complementary and alternative medical therapies in the United States. Ann Intern Med 2001;135:262-268.

7 Berman B: A 60-year-old woman considering acupuncture for knee pain. JAMA 2007;297:1697-1707.

$\checkmark 5$ Witt C, Brinkhaus B, Jena S, Linde K, Streng A, Wagenpfeil S, et al: Acupuncture in patients with osteoarthritis of the knee: a randomised trial. Lancet 2005;366:136-143.

6 Manheimer E, Linde K, Lao L, Bouter LM, Berman BM: Meta-analysis: acupuncture for osteoarthritis of the knee. Ann Intern Med 2007;146:868-877.

7 Ezzo JM, Richardson MA, Vickers A, Allen C, Dibble SL, Issell BF, et al: Acupuncture-point stimulation for chemotherapy-induced nausea or vomiting. Cochrane Database Syst Rev 2006;CD002285.

8 Ezzo J, Streitberger K, Schneider A: Cochrane systematic reviews examine P6 acupuncture-point stimulation for nausea and vomiting. J Altern Complement Med 2006;12:489-495.

9 McCarney RW, Brinkhaus B, Lasserson TJ, Linde $\mathrm{K}$ : Acupuncture for chronic asthma. Cochrane Database Syst Rev 2004;CD000008.

10 White A, Moody R: The effects of auricular acupuncture on smoking cessation may not depend on the point chosen - an exploratory meta-analysis. Acupunct Med 2006;24:149-156.

11 Birch S, Hesselink JK, Jonkman FA, Hekker TA Bos A: Clinical research on acupuncture. Part 1. What have reviews of the efficacy and safety of acupuncture told us so far? J Altern Complement Med 2004;10:468-480.

12 Ernst E, White AR: Prospective studies of the safety of acupuncture: a systematic review. Am J Med 2001;110:481-485.

13 Ernst E, White A: Life-threatening adverse reactions after acupuncture? A systematic review. Pain 1997;71:123-126.

14 Norheim AJ: Adverse effects of acupuncture: a study of the literature for the years 1981-1994. J Altern Complement Med 1996;2:291-297.
15 Norheim AJ, Fonnebo V: Acupuncture adverse effects are more than occasional case reports: Results from questionnaires among 1135 randomly selected doctors, and 197 acupuncturists. Complement Ther Med 1996;4:8-13.

16 Niggemann B, Gruber C: Side-effects of complementary and alternative medicine. Allergy 2003;58: 707-716.

17 White A:Towards greater safety in acupuncture practice - a systems approach. Acupunct Med 2004;22: 34-39.

18 MacPherson H, Thomas K, Walters S, Fitter M: The York acupuncture safety study: prospective survey of 34,000 treatments by traditional acupuncturists. BMJ 2001;323:486-487.

19 Yamashita H, Tsukayama H: Safety of acupuncture practice in Japan: patient reactions, therapist negligence and error reduction strategies. eCAM 2007: [nem086]. http://ecam.oxfordjournals.org/cgi/content/abstract/nem086v1.

20 de Groot M: Acupuncture: complications, contraindications and informed consent. Forsch Komplementarmed Klass Naturheilkd 2001;8:256-262.

21 Peuker E, Gronemeyer D: Rare but serious complications of acupuncture: traumatic lesions. Acupunct Med 2001;19:103-108.

22 Peuker ET, White A, Ernst E, Pera F, Filler TJ: Traumatic complications of acupuncture - therapists need to know human anatomy. Arch Fam Med 1999;8:553-558.

23 MacPherson H, Lewith GT: Reporting adverse events following acupuncture. Physiotherapy 2001;87: 21-24.

24 Yamashita H, Tsukayama H, White AR, Tanno Y, Sugishita C, Ernst E: Systematic review of adverse events following acupuncture: the Japanese literature. Complement Ther Med 2001;9:98-104.

25 Parzeller M, Wenk M, Zedler B, Rothschild M: Aufklärung und Einwilligung bei ärztlichen Eingriffen. Dtsch Arztebl 2007;104:A-576.

26 Odsberg A, Schill U, Haker E: Acupuncture treatment: side effects and complications reported by Swedish physiotherapists. Complement Ther Med 2001;9:17-20.

27 Bensoussan A, Myers SP, Carlton AL: Risks associated with the practice of traditional Chinese medicine: an Australian study. Arch Fam Med 2000;9: 1071-1078.

28 Melchart D, Weidenhammer W, Streng A, Reitmayr S, Hoppe A, Ernst E, et al: Prospektive investigation of adverse effects of acupuncture in 97,733 patients. Arch Intern Med 2004;164:104-105.
29 White A, Hayhoe S, Hart A, Ernst E: Adverse events following acupuncture: prospective survey of 32,000 consultations with doctors and physiotherapists. BMJ 2001;323:485-486.

30 Witt CM, Brinkhaus B, Jena S, Selim D, Straub J, Willich SN: Wirksamkeit, Sicherheit und Wirtschaftlichkeit der Akupunktur - ein Modellvorhaben mit der Techniker Krankenkasse. Dtsch Arztebl 2006;103:196-202.

31 Witt C, Brinkhaus B, Jena S, Selim D, Löbel S, Willich SN: Modellvorhaben Akupunktur der Techniker Krankenkasse und der dem Modellvorhaben beigetretenen Krankenkassen. Z Ärztl Fortbild Qualitätssich 2004;98:473-475.

32 European Commission: Enterprise and Industry Directorate-General: A Guideline on Summary of Product Characteristics. European Commission, 2005. http://ec.europa.eu/enterprise/pharmaceuticals/eudralex/vol-2/c/spcguidrev1-oct2005.pdf.

-33 Bulen JA Jr: 2003 Greenwall Bioethics Award. Complementary and alternative medicine. Ethical and legal aspects of informed consent to treatment. J Leg Med 2003;24:331-358.

34 Schwickert M, Muller H, Rampp T, Dobos G: [Informed consent in complementary and alternative medicine]. Dtsch Med Wochenschr 2006;131: 1047-1049.

35 MacPherson H, Scullion A, Thomas KJ, Walters S: Patient reports of adverse events associated with acupuncture treatment: a prospective national survey. Qual Saf Health Care 2004;13:349-355.

36 White A, Hayhoe S, Hart A, Ernst E: Adverse events following acupuncture: prospective survey of 32,000 consultations with doctors and physiotherapists. BMJ 2001;323:485-486.

37 Ernst E, White AR: Acupuncture may be associated with serious adverse events. BMJ 2000;320: 513-514.

38 Sato M, Katsumoto H, Kawamura K, Sugiyama $\mathrm{H}$, Takahashi T: Peroneal nerve palsy following acupuncture treatment: a case report. J Bone Joint Surg 2003;85:916-918.

39 Hanley JA, Lippman-Hand A: If nothing goes wrong, is everything all right? Interpreting zero numerators. JAMA 1983;249:1743-1745.

40 Eypasch E, Lefering R, Kum CK, Troidl H: Probability of adverse events that have not yet occurred: a statistical reminder. BMJ 1995;311:619-620. 